First publ. in: Journal of management 35 (2009), 1, pp. 94-111

\title{
Antecedents of Day-Level Proactive Behavior: A Look at Job Stressors and Positive Affect During the Workday ${ }^{\dagger}$
}

\author{
Charlotte Fritz* \\ Bowling Green State University, Department of Psychology, Bowling Green, OH 43403 \\ Sabine Sonnentag \\ University of Konstanz, Germany
}

This study extends research on proactive behavior at work by examining the extent to which job stressors (time pressure and situational constraints) and affective experiences during the workday are associated with proactive behaviors on the same and the following workday. Results from civil service employees who filled in surveys over 4 consecutive workdays indicated that situational constraints were positively associated with proactive behavior on the same workday. In addition, positive mood was significantly related to proactive behavior on the same and the following workday.

Keywords: proactive behavior; positive affect; time pressure; work stressors

Because of frequent changes in the demands posed on organizations and uncertainty in the work environment, behaviors that are self-directed and proactive have become increasingly important (Aragon-Correa, 1998). Such proactive behaviors include a "calculated, deliberate decision process" (Morrison \& Phelps, 1999), which can be motivated by work characteristics as well as by person-related variables (Fay \& Frese, 2001; Morrison \& Phelps, 1999; Parker,

\footnotetext{
$†$ We are grateful to Maike Debus and Oliver Langner for their help with data collection and data entry and to Sandra Ohly, Bing C. Lin, Russell Cropanzano, and two anonymous reviewers for helpful comments on earlier versions of this article.
}

*Corresponding author. E-mail address: fritzc@bgsu.edu

Journal of Management, Vol. 35 No. 1, February 2009 94-111 DOI: $10.1177 / 0149206307308911$

(C) 2009 Southern Management Association. All rights reserved. 
Williams, \& Turner, 2006). This study adds to research on proactive behavior by focusing on the predictive role of job stressors as well as affective experiences within 2 workdays. Specifically, we examine the extent job stressors and positive mood on a given workday are associated with proactive behaviors during the same and the following workday. Finding such short-term antecedents of proactive behaviors can help in further explaining the underlying processes that motivate the initiation of such behaviors on a day-to-day basis.

\section{Proactive Behaviors at Work}

The ongoing changes in organizations, markets, work processes, and products call for a reconsideration of the traditional view of individual work performance (Ilgen \& Pulakos, 1999). Because it is impossible to specify in advance all the behaviors necessary for the achievement of organizational goals, proactive behaviors at work are especially important. Proactivity refers to the extent to which an individual takes self-directed action to anticipate or initiate change in the work system or work roles (Griffin, Neal, \& Parker, 2007) and to support personal or organizational effectiveness (Watson \& Clark, 1992). For example, an employee may develop ways to fulfill tasks more efficiently or improve procedures to increase costumer satisfaction. Being proactive includes "taking initiative in improving current circumstances or creating new ones; it involves challenging the status quo rather than passive adapting to present conditions" (Crant, 2000, p. 436).

Proactive behaviors can add to organizational effectiveness (Axtell et al., 2000; Griffin et al., 2007; Rank, Pace, \& Frese, 2004). For example, high levels of personal initiative are associated with the generation of creative ideas (Binnewies, Ohly, \& Sonnentag, in press; Frese, Teng, \& Wijnen, 1999). In addition, proactive behaviors may help in changing current work situations and may improve overall long-term working conditions (Frese, Garst, \& Fay, 2007). Proactive behaviors of an employee may impact not only individual effectiveness but also the effectiveness on a group or even organizational level (Griffin et al., 2007). This implies that such selfstarting and future-oriented behaviors initiated by an employee can lead to changes for the individual as well as the whole organization. For example, enhanced work efficiency and improved costumer care may help overall organizational effectiveness. Thus, organizations need employees who show proactive behavior by identifying problems and aiming at solving them.

Research has provided evidence that employees show proactive behavior such as seeking feedback, taking initiative, actively adapting to new environments, expanding roles, or taking charge (Grant \& Ashford, in press). In each case, the employee actively tries to shape change and initiate individual and organizational development instead of passively reacting to work conditions (Grant \& Ashford, in press). In our study, we focused on one aspect of proactive behavior, namely, taking charge. Taking charge has been defined as "voluntary and constructive efforts, by individual employees, to effect organizationally functional change with respect to how work is executed within the contexts of their jobs, work units, or organizations" (Morrison \& Phelps, 1999: 403). Taking charge is discretionary, is change oriented, and focuses on improvement. Examples include eliminating redundant or unnecessary procedures, introducing new approaches to improve efficiency, and suggesting the change of counterproductive organizational rules (Morrison \& Phelps, 1999). 
Lately, theoretical assumptions regarding performance-related behaviors have shifted attention to more short-term processes (Beal, Weiss, Barros, \& MacDermid, 2005). Although recent research on proactive behaviors has started looking at predictors at the day level (Sonnentag, 2003), research on short-term processes regarding proactive behavior is still sparse. There are several reasons for why it is of interest and importance to examine daylevel proactive behavior and its predictors. First, focusing on day-level proactive behavior may help researchers understand the processes underlying the initiation of individual proactive behaviors. Specifically, which situations at work trigger the initiation of proactive behavior? For example, do specific job stressors on a workday such as time pressure and situational constraints increase or hinder employee proactivity on that workday? Second, assessments of day-level proactive behavior and their antecedents may reveal if such shortterm processes are parallel to assessments of more stable predictors as well as more stable proactive behavior. Specifically, factors that may motivate or hinder proactive behavior in the long term may not be the same factors that foster or impair proactive behavior on a daily basis. For example, high levels of role conflict on the day level may discourage the employee from proactive behaviors, whereas when adopting a long-term perspective, the individual will try to become proactive and change his or her work situation to reduce the level of role conflict. Third, measuring proactivity and its predictors once or twice per workday allows for measurements that are closer to the actual experience and behavior and therefore have less bias due to retrospective reporting. Thus, this study focuses on short-term intervals, specifically on proactivity within 1 or 2 workdays.

\section{Relationships Between Job Stressors and Proactivity}

When addressing job stressors as predictors of proactive behavior at work, scholars so far have examined rather stable job stressors (Fay \& Sonnentag, 2002; Ohly, Sonnentag, \& Pluntke, 2006; Sonnentag, 2003; Turner, Parker, \& Williams, 2002). However, because in these studies a person's general (i.e., chronic) level of job stressors was assessed, we do not know whether the experiences of job stressors is associated with the initiation of proactive behavior within a relatively short time interval. It might be that job stressors stimulate proactive behavior in the long run, but within single days, there might be even a negative association because the immediate need of dealing with the stressors leaves no time or cognitive resources for engaging in proactive behavior. To gain more insight in the relationship between job stressors and proactive behavior, it is therefore necessary to assess both job stressors and proactive behavior with respect to the same time interval, for example, by using day-specific measures of job stressors and proactive behavior. We do so in this study.

Earlier studies indicated that job demands such as time pressure are associated with higher personal initiative, one form of proactive behavior (Fay \& Sonnentag, 2002; Sonnentag, 2003). In our study that examined the relationship between job stressors and proactivity within shorter time intervals ( 1 or 2 workdays), we focused on time pressure and situational constraints as possible job stressors. We chose these two job stressors because research indicates that both stressors are highly common in the work setting (Jex, 1998) and are often associated with decreased health and well-being (De Lange, Taris, Kompier, 
Houtman, \& Bongers, 2003; Peters, O’Connor, Eulberg, \& Watson, 1988; Sparks, Cooper, Fried, \& Shirom, 1997).

Time pressure refers to the extent to which the employee experiences that he or she needs to work at a high speed to fulfill all work tasks (Baer \& Oldham, 2006; Kinicki \& Vecchio, 1994). Situational constraints can be defined as conditions in the work environment that hinder performance because of impaired organizational processes or inadequate tools and supplies (Fay \& Sonnentag, 2002). They interfere with the translation of skills and motivation into work tasks and may impede the achievement of work-related goals. We assume that higher levels of time pressure and situational constraints are associated with a higher level of proactive behavior. Although such a positive relationship may be counterintuitive at first, research on more stable job demands and proactivity seem to support this idea (Fay \& Sonnentag, 2002; Ohly et al., 2006; Sonnentag, 2003). One explanation for such a "positive" relationship refers to the dynamics of action regulation (Frese \& Zapf, 1994), implying that time pressure and situational constraints actually promote proactive behavior to ensure long-term goal attainment. Specifically, time pressure can be described as "overtaxing regulations" because it may call for working at high speed or intensity (Fay, Sonnentag, \& Frese, 2001). Overtaxing regulations require more resources and increased energy to ensure goal achievement.

Situational constraints can be described as regulation obstacles (Fay et al., 2001) or work barriers (Greiner, Ragland, Krause, Syme, \& Fisher, 1997) "which make it harder or even impossible to pursue a goal or to regulate an action" (Frese \& Zapf, 1994: 311). Such obstacles or barriers impede job performance and demand additional effort to ensure the achievement of goals and the completion of tasks (Frese \& Zapf, 1994; Greiner et al., 1997). Situational constraints act as barriers because they may lead to extra work (Leitner \& Resch, 2005). As a result these constraints can hinder task performance or may result in an interruption of the task fulfillment process (Greiner et al., 1997).

Thus both types of job stressors, time pressure as well as situational constraints, indicate a suboptimal situation that hinders action regulation (Fay et al., 2001) and impedes immediate goal achievement. However, because goal achievement is important for individual performance as well as for organizational effectiveness, the employee should aim at securing the achievement of those goals. One strategy to enhance goal achievement is proactivity. Proactive behaviors aim at changing work situations so that the achievement of work goals becomes possible. The initiation of proactive behavior on a single workday can then be described as a mechanism to ensure goal achievement when there are obstacles on the way toward those goals.

Hypothesis 1: Time pressure on a specific workday is positively related to proactive behavior during the same workday.

Hypothesis 2: Situational constraints on a specific workday are positively related to proactive behavior during the same workday.

\section{Relationships Between Affective Experiences and Proactivity}

With regard to individual-level factors that may be associated with proactive behaviors, research has primarily examined rather stable person-related factors such as proactive personality (Parker et al., 2006) or control orientation (Fay \& Frese, 2001). In this study, we examine 
if employees who experience high levels of positive mood on one workday will show higher levels of proactivity on the same and the next workday.

Affective experiences that result from daily events and situations play an important role in everyday work life (Barsade, 2002; Isen \& Baron, 1991). Accordingly, theoretical research on emotions in the workplace suggests that momentary affect and emotions influence behavior and performance at work (Weiss \& Cropanzano, 1996). However, most research so far has focused on attitudinal rather than performance-related outcomes (Brief, Butcher, \& Roberson, 1995; Fisher, 2000). Studies on relationships between day-level affect and proactive behaviors at work are nearly nonexistent (Ilies, Scott, \& Judge, 2006). However, research suggests that in the work context, affect might even be stronger related to proactive behavior than to task performance, because proactivity is not under close supervisory control (George \& Brief, 1992).

Regarding affective experiences, researchers differentiated between positive and negative affect, which are conceptualized as two related but empirically distinct dimensions (Burke, Brief, George, \& Roberson, 1989), and refer to two distinct systems within the brain (Fisher, 2002). On a daily basis, positive and negative mood are manifestations of short-term affect. High positive mood refers to "a state of high energy, full concentration, and pleasurable engagement" (Watson, Clark, \& Tellegen, 1988: 1063) and can be characterized by feeling excited, inspired, or active. In contrast, high negative mood can be described as a state of "subjective distress and unpleasurable engagement that subsumes a variety of aversive mood states" (p. 1063) and refers to feelings of being afraid, upset, or hostile (Watson et al., 1988). In this study we focus on positive mood because we assume that it is specifically relevant for proactive behavior at work. However, we control for negative mood in our analysis to support our assumption: High level of positive mood and not the lack of negative mood is necessary for proactive behavior.

Several theoretical approaches lend support to the assumption of a relationship between positive mood and proactive behavior. One theoretical approach refers to Fredrickson's (1998) "broaden-and-build model." The model assumes that positive mood acts as a resource that broadens a person's thought-action repertoire, meaning the range of attention, cognition, and action. This broadening effect can then result in increased physical, intellectual, and social resources (Fredrickson, 1998, 2001). These resources may even counteract the narrowing effects of negative affect (Fredrickson, 1998) and help initiate effortful and goaldirected activities such as proactive behavior.

Second and related to the first explanation, positive affect may facilitate performancerelated outcomes because these outcomes are associated with higher levels of physiological and psychological resources such as energy and attention (Rothbard \& Wilk, 2006). Thus, positive mood fosters proactive behaviors at work because of increased levels of energy and attention, which are necessary for the self-regulatory, goal-oriented, and persistent aspects in proactive behavior. Accordingly, Rothbard and Wilk (2006) found that positive mood during a workday was positively associated with more discretionary aspects of job performance. The energetic arousal component may also enhance individuals' optimism regarding goal achievement, and therefore individuals will set higher performance goals when they experience high positive affect (Ilies \& Judge, 2005). This optimism may then translate into the optimism that the initiation of proactive behaviors will lead to the expected positive outcome. 
Third, positive affect fosters approach behavior (Cacioppo, Gardner, \& Berntson, 1999). As a result, individuals may actively engage with their environment. So, again, positive mood seems to be associated with the energy that motivates individuals to aim for a specific goal. Thus, positive mood may facilitate approach behaviors and active engagement with the environment in form of proactive behavior aiming at changing the current situation.

Hypothesis 3: Positive mood during a specific workday is positively associated with proactive behavior during the same workday over and above the effects of job stressors.

Research on day-level affective experiences indicates that affective experiences at work have an impact on experiences and behaviors in the nonwork context (Heller \& Watson, 2005; Judge \& Ilies, 2004; Scott \& Judge, 2006; Williams \& Alliger, 1994). Extending this idea we assume that individuals who experience high levels of positive mood during one workday will show higher levels of proactivity also during the following workday. Such a delayed relationship of mood on proactive behavior may have several reasons. First, the experienced mood on a workday may be a result of experienced events or job stressors at work (Weiss \& Cropanzano, 1996). These stressors and events or their consequences may still be present when the employee returns to work the following workday. As a result, the positive mood that was present the first workday may be reactivated on the following day, thereby activating self-regulatory resources that help initiating proactive behavior. Second, when returning to work the following workday, "stimuli" at work may trigger the memory of the positive affective state the employee was in the day before. This memory reactivates the positive mood, thereby freeing self-regulatory resources and fostering approach behavior that, in return, help initiate proactive behavior. Furthermore, it may be that proactive projects initiated on one day may not be completed within a single day. As a result, proactive behavior will be reinitiated on the following day to finish these projects.

Hypothesis 4: Positive mood during a specific workday predicts proactive behavior during the following workday.

\section{Method}

\section{Study Design}

Altogether, our study included seven measurement occasions. On a Monday, we assessed demographic variables (age, gender, leadership position) and trait proactivity. From Tuesday through Thursday we included two measurement occasions per day. Specifically, at lunchtime, we measured proactive behavior as well as positive and negative mood during the morning of the respective workday. In addition, participants reported their perceived levels of time pressure and situational constraints for the respective workday. At the end of the workday, we measured employees' proactive behavior as well as positive and negative mood during the afternoon of the respective workday. We decided not to include measures on Friday because civil service employees often end their workday early on Fridays, which may have impacted relationships between morning and afternoon measures. Overall, the day-level 
measurements allowed us to examine lagged relationships between measures in the morning of a specific workday (assessed at lunchtime) and measures in the afternoon of the same workday (assessed at the end of the workday). In addition, we were able to study lagged relationships between measures in the afternoon of one workday and measures during the morning of the following workday.

\section{Participants and Procedure}

Participants were civil service employees from different 23 German cities. Organizations in each city were contacted by phone and told that if they indicated an interest in participating, they would receive a sample survey package. After organizations agreed to participate in our study, which was framed as research on "experiences at work," individuals were recruited through an e-mail letter at their workplace. Survey packages that were sent out consisted of an information letter, four clearly distinguishable survey booklets, and a stamped return envelope preaddressed to the researchers. The information letter stressed the voluntary and confidential nature of their responses. The first survey booklet was filled in on a Monday and included questions regarding dispositional variables and demographic information. The second, third, and fourth survey booklet were filled in on Tuesday, Wednesday, and Thursday, respectively, and assessed day-level job stressors, mood, and proactive behavior. In the first part of each booklet (which was filled in after lunch break), individuals reported levels of mood and proactive behavior during the morning and the levels of job stressors during the day. In the second part, which was filled in at the end of the workday, participants gave ratings on mood and proactive behavior during the afternoon. Each part included detailed instructions about when and how to complete the survey packets.

Out of the 214 questionnaires that were sent out, 172 were returned to the researchers (response rate $=80.37 \%$ ). The sample consisted of employees who mostly did clerical administrative work in departments such as sanitation department, welfare office, public health department, or the social welfare office. The sample included $51.70 \%$ women; the mean age of participants was 39.63 years $(S D=11.40)$, and mean reported job experience was 17.17 years $(S D=11.29)$. About $38 \%$ of the sample held a university degree, and $37 \%$ had a leadership position. Average contract working time per week was 38.79 hours $(S D=1.87)$ with the amount of overtime being 3.16 hours $(S D=2.95)$ per week on average.

\section{Measures}

Job stressors. Measures of job stressors included scales regarding job demands (time pressure and situational constraints) and were based on scales developed by Semmer (1984). Both measures of job stressors were assessed at noon and asked participants to rate the amount of time pressure (e.g., "Today I am under time pressure") and situational constraints (e.g., "Today I have to work with documents and information that are incomplete and outdated") on that specific workday on a 5-point rating scale from 1 (not true at all) to 5 (absolutely true). Cronbach's alpha at the three measurement occasions ranged between .88 and .91 for time pressure and between .82 and .87 for situational constraints. 
Positive mood. Positive mood was gauged with the 10 positive-affect items from the Positive and Negative Affect Schedule (Watson et al., 1988). Participants were asked on a 5point rating scale from 1 (not at all) to 5 (very much) how they felt by referring to an adjectives list indicating positive affect (e.g., enthusiastic, alert, active). Cronbach's alpha was .89 for all measurements regarding positive mood during the morning and ranged between .88 and .90 for positive mood in the afternoon.

Proactive behavior. We assessed taking charge (Morrison \& Phelps, 1999) in the morning and the afternoon as an indicator of proactive behavior. The scale included 10 items (e.g., "I tried to adopt improved procedures for doing my job"; "I tried to correct a faulty procedure or practice"; I tried to introduce new structures, technologies, or approaches to improve efficiency") to be answered on 5-point rating scales from 1 (not true at all) to 5 (absolutely true). Reliabilities ranged between .90 and .91 in the morning and .90 and .92 in the afternoon.

Control variables. To ensure that day-level taking charge could actually be explained by day-level job stressors and day-level positive mood above and beyond stable aspects of taking charge, we controlled for dispositional taking charge. Thus, we measured the general level of employees' taking charge in the first survey booklet to be completed before responding to the day-specific items (Morrison \& Phelps, 1999). Cronbach's alpha was .89.

Research indicates that common method variance may have a significant impact on relationships between measures of different constructs. One suggested technique to control for common method bias is including a time lag between the measurement of the predictor and the outcome variable (Podsakoff, MacKenzie, Lee, \& Podsakoff, 2003). We amended to this suggestion by assessing the predictor variables (job stressors, positive mood) and proactive behavior at different measurement occasions. In addition, partialling out participants' affective states may help in further controlling for common method bias (Podsakoff et al., 2003). Accordingly, we controlled for day-level negative mood to at least partially rule out threats to validity because of common method variance. Negative mood was measured with 10 negative-affect items from the Positive and Negative Affect Schedule (Watson et al., 1988). As with positive mood, participants were asked on a 5-point rating scale how they felt referring to adjectives indicating negative affect (e.g., scared, nervous, hostile). Cronbach's alpha ranged between .86 and .91 during the morning and between .88 and .89 during the afternoon. Because we assumed that employees with a supervisory position show higher levels of proactivity, we controlled for having a supervisory position in the analysis. Finally, we controlled for age and gender.

\section{Data Analysis}

We used multilevel analysis (Bryk \& Raudenbush, 1992) to analyze our data assuming a hierarchical data structure with two levels of analysis. Level 1 data included day-specific measurements, such as situational constraints. Level 2 referred to data that were relatively stable and specific to the person, such as dispositional proactive behavior. Thus, day-level data (mood and taking charge during the morning and the afternoon) were nested within 
person-level data (dispositional taking charge). Level 1 data were centered around the sample's mean. Based on our specific research design, we then used multilevel analyses to examine (a) how job stressors and positive mood measured at noon of a specific workday (Time $t$ ) predicted proactive behavior during the afternoon of the same workday (Time $t+1$ ) and (b) how positive mood in the afternoon of a specific workday (Time $t+1$ ) predicted proactive behavior during the morning of the following workday (Time $t+2$ ).

\section{Results}

Means, standard deviations, and intercorrelations are presented in Table 1.

\section{Effects of Day-Level Job Stressors}

Using multilevel analyses, we examined if day-level job stressors — namely, time pressure and situational constraints - predicted proactive behavior during the afternoon of a workday. Specifically, in the Null Model the intercept was the only predictor. In Model 1, we entered the control variables, namely, age, gender, supervisory position, negative mood during the morning of the workday, and trait proactive behavior. Hypothesis 1 predicted that day-level time pressure would be related to levels of proactive behavior throughout the workday. Thus, we examined if time pressure on a workday (measured at noon) was related to taking charge during the afternoon of the same workday. Results are shown in Table 2. Analyses indicated that day-level time pressure was significantly related to taking charge during the afternoon when entered in Model 2. Specifically, higher time pressure was associated with higher levels of proactive behaviors. However, when positive mood was entered into the equation (Model 3) the $t$ value for time pressure was no longer significant. Thus, Hypothesis 1 was not supported.

In Hypothesis 2, we predicted that day-level situational constraints (measured at noon) would be associated with proactive behavior throughout the same workday. Thus, we examined the extent to which situational constraints predicted taking charge during the afternoon of the same workday. Results indicated that higher levels of situational constraints were significantly associated with higher levels of proactivity, thereby supporting Hypothesis 2 . This relationship remained significant even after entering positive affect into the analysis.

\section{Effects of Day-Level Affective Experiences}

Hypothesis 3 predicted that positive mood during one workday would be associated with proactive behavior during the same workday over and above the effects of job stressors. Results of multilevel analyses indicated that positive mood during the morning of a workday was positively associated with taking charge during the afternoon of the same day. This relationship was significant over and above the effects of demographic variables, trait proactivity, negative mood, and day-level job stressors. 
Table 1

Means, Standard Deviations, and Zero-Order Correlations Between Study Variables

\begin{tabular}{|c|c|c|c|c|c|c|c|c|c|c|c|c|c|}
\hline Variable & M & SD & 1 & 2 & 3 & 4 & 5 & 6 & 7 & 8 & 9 & 10 & 11 \\
\hline 1. Age & 39.63 & 11.40 & & & & & & & & & & & \\
\hline 2. Gender & 0.48 & 0.50 & $0.31 * *$ & & & & & & & & & & \\
\hline 3. Leadership position & 1.63 & 0.49 & $-0.38 * *$ & $-0.32 * *$ & & & & & & & & & \\
\hline 4. Trait taking charge & 4.60 & 0.96 & $0.15^{*}$ & $0.15^{*}$ & $-0.18^{*}$ & & & & & & & & \\
\hline 5. Time pressure & 2.73 & 1.06 & 0.14 & 0.11 & $-0.33 * *$ & 0.03 & & & & & & & \\
\hline 6. Situational constraints & 1.95 & 0.94 & 0.12 & $0.15^{*}$ & $-0.16^{*}$ & 0.11 & $0.32 * *$ & & & & & & \\
\hline 7. Positive mood in the morning & 3.23 & 0.63 & 0.10 & -0.06 & 0.05 & $0.18^{*}$ & 0.10 & 0.12 & & & & & \\
\hline 8. Positive mood in the afternoon & 3.17 & 0.64 & 0.04 & -0.05 & 0.00 & $0.21 *$ & 0.08 & 0.08 & 0.85 & & & & \\
\hline 9. Negative mood in the morning & 1.33 & 0.45 & -0.10 & 0.12 & -0.10 & 0.01 & $0.24 * *$ & 0.12 & $-0.32 * *$ & $-0.25^{* *}$ & & & \\
\hline 10. Negative mood in the afternoon & 1.30 & 0.44 & -0.09 & 0.08 & $-0.15^{*}$ & 0.04 & $0.29 * *$ & 0.14 & $-0.28 * *$ & $-0.25^{* *}$ & $0.91 * *$ & & \\
\hline 11. Taking charge in the morning & 2.91 & 1.24 & -0.01 & 0.10 & $-0.17^{*}$ & $0.41 * *$ & $0.26^{* * *}$ & $0.35 * *$ & $0.35^{* *}$ & $0.34 * *$ & 0.12 & 0.12 & \\
\hline 12. Taking charge in the afternoon & 2.76 & 1.23 & -0.04 & 0.07 & $-0.16^{*}$ & $0.39 * *$ & $0.32 * *$ & $0.35 * *$ & $0.34 * *$ & $0.38 * *$ & 0.12 & $0.15^{*}$ & $0.90^{* *}$ \\
\hline
\end{tabular}

Note: $N=162-172$. Gender: $0=$ female, $1=$ male. Leadership position: $1=$ yes, $2=$ no. $* p<.05$.

$* * p<.01$. 
Table 2

Multilevel Estimates for Models Predicting Taking Charge in the Afternoon

\begin{tabular}{|c|c|c|c|c|c|c|c|c|c|c|c|c|}
\hline \multirow[b]{2}{*}{ Variable } & \multicolumn{3}{|c|}{ Null Model } & \multicolumn{3}{|c|}{ Model 1} & \multicolumn{3}{|c|}{ Model 2} & \multicolumn{3}{|c|}{ Model 3} \\
\hline & Estimate & $S E$ & $t$ & Estimate & $S E$ & $t$ & Estimate & $S E$ & $t$ & Estimate & $S E$ & $t$ \\
\hline Intercept & 2.75 & 0.10 & $28.75^{* *}$ & 2.76 & 0.09 & $31.83^{* *} *$ & 2.76 & 0.08 & $34.21 * *$ & 2.76 & 0.08 & $36.03 * *$ \\
\hline Age & & & & -0.01 & 0.01 & -1.85 & -0.02 & 0.01 & $-2.18^{*}$ & -0.02 & 0.01 & $-2.48 *$ \\
\hline Gender & & & & 0.03 & 0.19 & 0.16 & -0.01 & 0.18 & -0.05 & 0.02 & 0.17 & 0.10 \\
\hline Leadership position & & & & -0.37 & 0.20 & -1.87 & -0.27 & 0.19 & -1.45 & -0.32 & 0.18 & -1.76 \\
\hline Trait taking charge & & & & 0.50 & 0.09 & $5.34 * *$ & 0.49 & 0.09 & $5.59 * *$ & 0.44 & 0.08 & $5.31 * *$ \\
\hline Negative mood in the morning & & & & 0.04 & 0.11 & 0.38 & -0.03 & 0.11 & -0.26 & 0.15 & 0.12 & 1.26 \\
\hline Time pressure & & & & & & & 0.10 & 0.05 & $2.16^{*}$ & 0.08 & 0.05 & 1.74 \\
\hline Situational constraints & & & & & & & 0.23 & 0.05 & $4.23 * *$ & 0.23 & 0.05 & $4.30 * *$ \\
\hline Positive mood in the morning & & & & & & & & & & 0.22 & 0.05 & $4.31 * *$ \\
\hline Deviance & & 1346.72 & & & 1313.75 & & & 1290.66 & & & 1271.04 & \\
\hline$\Delta$ Deviance & & & & & $32.97 * *$ & & & $23.10 * *$ & & & $19.61 * *$ & \\
\hline$\Delta d f$ & & & & & 5 & & & 2 & & & 1 & \\
\hline Level 1 intercept variance $(S E)$ & & $0.51(0.71)$ & & & $0.51(0.71)$ & & & $0.51(0.71)$ & & & $0.50(0.71)$ & \\
\hline Level 2 intercept variance $(S E)$ & & $1.34(1.16)$ & & & $1.10(1.03)$ & & & $0.89(0.94)$ & & & $0.79(0.89)$ & \\
\hline
\end{tabular}

$* p<.05$.

$* * p<.01$. 


\section{Delayed Effects of Affective Experiences}

Finally, in Hypothesis 4 we predicted that positive mood in the afternoon of one workday would be associated with proactive behavior the following workday. Results revealed that higher levels of positive mood on one workday were related to higher levels of taking charge on the following workday, again when controlling for demographic variables, trait proactivity, negative mood, and job stressors (on the same day, see Table 3).

In summary, results indicated that day-level job stressors (specifically situational constraints) and day-level positive mood were positively associated with proactive behavior on the same and the following workday.

\section{Discussion}

This study examined day-level predictors of taking charge at work. Specifically, we examined the extent to which job stressors (time pressure and situational constraints) and affective experiences (positive mood) on a workday predicted proactive behavior on the same and the following workday. Results indicated that situational constraints predicted taking charge throughout the workday. Specifically, we found a positive relationship, suggesting that higher levels of situational constraints were associated with higher levels of proactive behavior. Time pressure and situational constraints may indicate a suboptimal situation at work that can be changed through proactive behaviors.

Time pressure was no longer related to proactivity when positive was included as predictor. In this regard, our findings deviate from earlier research on relationships between time pressure and proactive behavior (Fay \& Sonnentag, 2002; Turner et al., 2002). The pattern of our findings may draw attention to differences in relationships between time pressure and proactive behavior depending on the time frame studied. Our results indicate that individuals who experience higher levels of time pressure during a single workday do not show higher levels of proactive behavior on the same workday. Possibly, high levels of time pressure on a specific workday do not leave enough time available for the initiation of proactive behavior on the same workday. Instead, employees may focus on finishing the tasks they are already involved in on that workday.

Results from multilevel analyses further indicate that positive mood is positively related to proactive behaviors on the same and the following workday. Thus, positive mood may act as a self-regulatory resource that stimulates interaction with the environment to change the status quo. Such interactions then become visible in an increased level of proactive behaviors. Our results further indicated that positive mood predicted proactivity even after controlling for negative mood. Therefore, it seems that a high level of positive affect (as opposed to a low level of negative affect) is associated with the initiation of proactivity. Because research has provided extensive evidence of lagged effects of negative experiences at work (Sonnentag \& Frese, 2003), our results regarding lagged effects between positive mood and proactive behavior are especially fruitful as they indicate lagged effects of positive experience that even translate into actual positive behavior. In that sense our results fit well into recent research on positive psychology (Fredrickson, 2001) or positive organizational scholarship (Turner, Barling, \& Sachaatos, 2002). 
Table 3

Multilevel Estimates for Models Predicting Taking Charge in the Morning (Spillover)

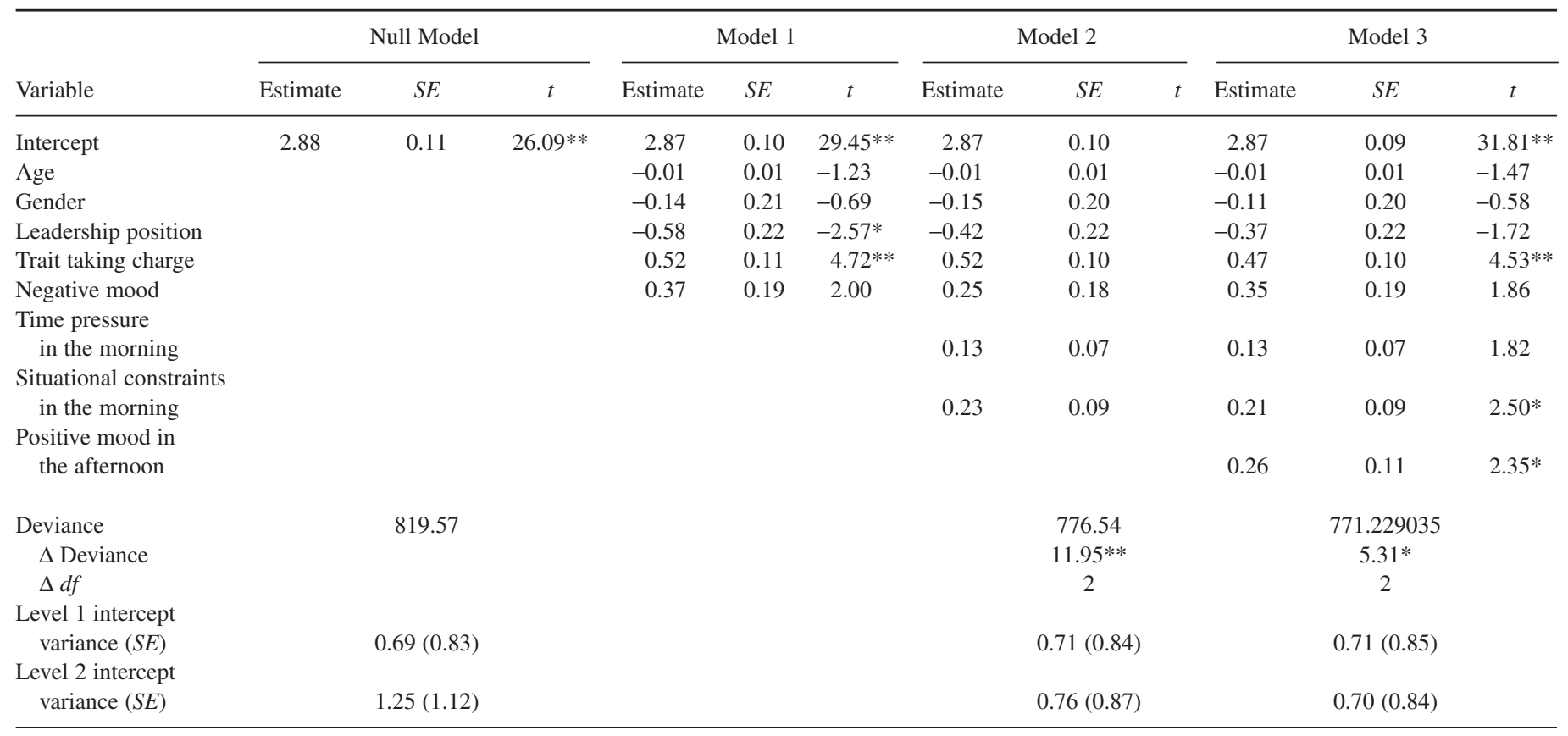

$* p<.05$.

$* * p<.01$. 


\section{Limitations}

One limitation of our study is the sole use of self-reports to measure the variables of interest. This approach includes the danger of inflated relationships between study variables because of common method bias (Podsakoff et al., 2003). We tried to at least partially rule out such threats to validity by controlling for day-level negative mood as suggested by Podsakoff et al. (2003). Future research also may include measurements from other sources such as coworker or supervisor reports of proactive behavior. However, it may be particularly difficult to get coworker or supervisor reports several times a day. In addition, the particular coworker or supervisor would have to monitor the focal participant quite closely during each measurement period to be able to evaluate the person's proactive behavior. One may assume that self-reports refer more to intentions than to actual behaviors indicating that respondents already give themselves credit for intending to show a certain behavior. Although this process may be a clear limitation of self-reports, reports from other sources may not be without bias either. Specifically, such reports may be colored by interpretative processes that include their own biases. For example, a coworker or supervisor may rely more on a person's traits than his or her actual behavior during a certain period. As a result, we may not be able to take for granted that coworkers and supervisors will be able to provide proactivity measures that are more valid than self-reports. Thus, there seem to be two debatable sides to the issue of self- versus other-reports. For future research, we recommend including measures of self-reports as well as reports from other sources.

Another weakness of our study is the use of paper-based surveys. Because this approach relied on participant's reported compliance with instructions and may raise concerns regarding its validity, future research may aim at using electronic diaries that allow the exact documentation of response time. However, recent research indicates that paper-based diaries are not necessarily more prone to measurement bias than electronic formats of data collection. Specifically, empirical findings suggest that both methods (with few exceptions) seem to be associated with psychometrically equivalent findings (Green, Rafaeli, Bolger, Shrout, \& Reis, 2006).

\section{Implications for Research and Practice}

Based on the results from this study, several implications can be drawn. First, our study showed that situational constraints are related to proactive behavior on the same day. Future research may aim at examining in more detail the cognitive and motivational processes employees engage in when they respond with proactive behavior to situational constraints. Moreover, the experience of challenge may act as mediator between job stressors and proactive behavior (Ohly \& Fritz, 2007). Related to this possibility, one might suggest that we should have tested the role of positive mood as a mediator between job stressors and proactive behavior. Specifically, we could have tested if job stressors were related to positive mood, which in turn would be associated with proactive behavior. However, correlations already indicated that the job stressors (time pressure and situational constraints) were related to negative mood, whereas it was positive mood that was related to proactive behavior. These bivariate relationships made a test for mediation obsolete (Baron \& Kenny, 1986). 
Because positive mood is associated with proactive behaviors, organizations should try to enhance employees' positive affective experiences at work. Specifically, as the experience of fairness is related to positive affect at work (Judge \& Ilies, 2004; Weiss, Suckow, \& Cropanzano, 1999), organizations may want to pay close attention to the fair treatment of their employees.

Our findings indicated that job stressors were positively related to proactive behavior, meaning that factors in the work environment (such as situational constraints) that are associated with impairments in individual well-being (De Lange et al., 2003; Peters et al., 1988; Sparks et al., 1997) are simultaneously associated with individual behaviors that promote organizational effectiveness. Future research should aim at exploring possible factors in the work environment that enhance employee well-being as well as individual and organizational effectiveness. Specifically, studies may aim at understanding, in more detail, which specific situations and experiences at work foster or hinder proactive behaviors.

Furthermore, future research may extend findings regarding the role of person-related factors in proactive behavior (Parker et al., 2006), thereby focusing on stable factors such as personality variables as well as more short-term experiences such as motivational or emotional factors. Finding out which factors support or hinder day-level proactive behavior may give earlier possibilities for counteracting.

In summary, to gain more insight into relationships between job stressors as well as motivational or affective experiences and proactive behavior within a workday, it is important to examine job stressors, motivation, affect, and proactive behavior with respect to the identical time interval. This study contributed in understanding some processes underlying the initiation of proactive behavior within a single workday. Future research may extend our findings by studying additional job stressors or affective experiences, in particular discrete emotions.

\section{References}

Aragon-Correa, J. A. 1998. Strategic proactivity and firm approach to the natural environment. Academy of Management Journal, 41: 556-567.

Axtell, C. M., Holman, D. J., Unsworth, K. L., Wall, T. D., Waterson, P. E., \& Harrington, E. 2000. Shopfloor innovation: Facilitating the suggestion and implementation of ideas. Journal of Occupational and Organizational Psychology, 73: 265-285.

Baer, M., \& Oldham, G. R. 2006. The curvilinear relation between experienced creative time pressure and creativity: Moderating effects of openness to experience and support for creativity. Journal of Applied Psychology, 91: 963-970.

Baron, R. M., \& Kenny, D. A. 1986. The moderator-mediator variable distinction in social psychology research: Conceptual, strategic, and statistical considerations. Journal of Personality and Social Psychology, 51: 1173-1182.

Barsade, S. G. 2002. The ripple effect: Emotional contagion and its influence on group behavior. Administrative Science Quarterly, 47: 644-675.

Beal, D. J., Weiss, H. M., Barros, E., \& MacDermid, S. M. 2005. An episodic process model of affective influences on performance. Journal of Applied Psychology, 90: 1054-1068.

Binnewies, C., Ohly, S., \& Sonnentag, S. (in press). Taking personal initiative and communicating about ideas: What is important for the creative process and for creativity? European Journal of Work and Organizational Psychology. 
Brief, A. P., Butcher, A. H., \& Roberson, L. 1995. Cookies, disposition, and job attitudes: The effect of positive mood-inducing events and negative affectivity on job satisfaction in a field experiment. Organizational Behavior and Human Decision Processes, 62: 55-62.

Bryk, A. S., \& Raudenbush, S. W. 1992. Hierarchical linear models: Applications and data analysis methods. Thousand Oaks, CA: Sage.

Burke, M. J., Brief, A. P., George, J. M., \& Roberson, L. 1989. Measuring affect at work: Confirmatory analyses of competing mood structures with conceptual linkage to cortical regulatory systems. Journal of Personality and Social Psychology, 57: 1091-1102.

Cacioppo, J. T., Gardner, W. L., \& Berntson, G. G. 1999. The affect system has parallel and integrative processing components: Form follows function. Journal of Personality and Social Psychology, 76: 839-855.

Crant, J. M. 2000. Proactive behavior in organizations. Journal of Management, 26: 435-462.

De Lange, A. H., Taris, T. W., Kompier, M. A. J., Houtman, I. L. D., \& Bongers, P. M. 2003. "The very best of the millennium": Longitudinal research and the demand-control-(support) model. Journal of Occupational Health Psychology, 8: 282-305.

Fay, D., \& Frese, M. 2001. The concept of personal initiative: An overview of validity studies. Human Performance, 14: $97-124$.

Fay, D., \& Sonnentag, S. 2002. Rethinking the effects of stressors: A longitudinal study on personal initiative. Journal of Occupational Health Psychology, 7: 221-234.

Fay, D., Sonnentag, S., \& Frese, M. 2001. Stressors, innovation, and personal initiative: Are stressors always detrimental? In C. L. Cooper (Ed.), Theories of organizational stress: 170-189. New York: Oxford University Press.

Fisher, C. D. 2000. Mood and emotions while working: Missing pieces of job satisfaction? Journal of Organizational Behavior, 21: 185-202.

Fisher, C. D. 2002. Antecedents and consequences of real-time affective reactions at work. Motivation and Emotion, 26: 3-30.

Fredrickson, B. L. 1998. What good are positive emotions? Review of General Psychology, 2: 300-319.

Fredrickson, B. L. 2001. The role of positive emotions in positive psychology. American Psychologist, 56: 218-226.

Frese, M., Garst, H., \& Fay, D. 2007. Making things happen: Reciprocal relationships between work characteristics and personal initiative in a four-wave longitudinal structural equation model. Journal of Applied Psychology, 92: 1084-1102.

Frese, M., Teng, E., \& Wijnen, C. J. D. 1999. Helping to improve suggestion systems. Journal of Organizational Behavior, 20: 1139-1155.

Frese, M., \& Zapf, D. 1994. Action as the core of work psychology: A German approach. In H. C. Triandis, M. D. Dunnette, \& L. M. Hough (Eds.), Handbook of industrial and organizational psychology (2nd ed., Vol. 4): 271340. Palo Alto, CA: Consulting Psychologists Press.

George, J. M., \& Brief, A. P. 1992. Feeling good—doing good: A conceptual analysis of the mood at work-organizational spontaneity relationship. Psychological Bulletin, 112: 310-329.

Grant, A. M., \& Ashford, S. J. in press. The dynamics of proactivity at work. Research in Organizational Behavior.

Green, A. S., Rafaeli, E., Bolger, N., Shrout, P. E., \& Reis, H. T. 2006. Paper or plastic? Data equivalence in paper and electronic diaries. Psychological Methods, 11: 87-105.

Greiner, B. A., Ragland, D. R., Krause, N., Syme, S. L., \& Fisher, J. M. 1997. Objective measurement of occupational stress factors-an example with San Francisco urban transit operators. Journal of Occupational Health Psychology, 2: 325-342.

Griffin, M. A., Neal, A., \& Parker, S. K. (2007). A new model of work role performance: Positive behavior in uncertain and interdependent contexts. Academy of Management Journal, 50, 327-347.

Heller, D., \& Watson, D. 2005. The dynamic spillover of satisfaction between work and marriage: The role of time and mood. Journal of Applied Physiology, 90: 1273-1279.

Ilgen, D. R., \& Pulakos, E. D. 1999. The changing nature of performance: Implications for staffing, motivation, and development. San Francisco: Jossey-Bass.

Ilies, R., \& Judge, T. A. 2005. Goal regulation across time: The effects of feedback and affect. Journal of Applied Psychology, 90: 453-467.

Ilies, R., Scott, B. A., \& Judge, T. A. 2006. The interactive effects of personal traits and experienced states on intraindividual patterns of citizenship behavior. Academy of Management Journal, 49: 561-575. 
Isen, A. M., \& Baron, R. M. 1991. Positive affect as a factor in organizational behavior. In L. L. Cummings \& B. M. Staw (Eds.), Research in organizational behavior (Vol. 13):1-53. London: JAI.

Jex, S. M. 1998. Stress and job performance: Theory, research, and implications for managerial practice. Thousand Oaks, CA: Sage.

Judge, T. A., \& Ilies, R. 2004. Affect and job satisfaction: A study of their relationship at work and at home. Journal of Applied Psychology, 89: 661-673.

Kinicki, A. J., \& Vecchio, R. P. 1994. Influences on the quality of supervisor-subordinate relations: The role of time pressure, organizational commitment, and locus of control. Journal of Organizational Behavior, 15: 75-82.

Leitner, K., \& Resch, M. G. 2005. Do the effects of job stressors on health persist over time? A longitudinal study with observational stressor measures. Journal of Occupational Health Psychology, 10: 18-30.

Morrison, E. W., \& Phelps, C. C. 1999. Taking charge at work: Extra-role efforts to initiate workplace change. Academy of Management Journal, 42: 403-419.

Ohly, S., \& Fritz, C. (2007). Work characteristics, creativity, and proactive behavior: The mediating role of challenge. Manuscript submitted for publication.

Ohly, S., Sonnentag, S., \& Pluntke, F. 2006. Routinization, work characteristics and their relationships with creative and proactive behaviors. Journal of Organizational Behavior, 27: 257-279.

Parker, S. K., Williams, H. M., \& Turner, N. 2006. Modeling the antecedents of proactive behavior at work. Journal of Applied Psychology, 91: 636-652.

Peters, L. H., O’Connor, E. J., Eulberg, J. R., \& Watson, T. W. 1988. An examination of situational constraints in Air Force work settings. Human Performance, 1: 133-144.

Podsakoff, P. M., MacKenzie, S. B., Lee, J.-Y., \& Podsakoff, N. P. 2003. Common method biases in behavioral research: A critical review of the literature and recommended remedies. Journal of Applied Psychology, 88: 879-903.

Rank, J., Pace, V. L., \& Frese, M. 2004. Three avenues for future research on creativity, innovation, and initiative. Applied Psychology: An International Review, 53: 518-528.

Rothbard, N. P., \& Wilk, S. L. 2006, May. Waking up on the right side of bed: The influence of mood on work attitudes and performance. Paper presented at the 21st Annual Conference of the Society of Industrial and Organizational Psychology, Dallas, TX.

Scott, B. A., \& Judge, T. A. 2006. Insomnia, emotions, and job satisfaction: A multilevel study. Journal of Management, 32: 1-24.

Semmer, N. 1984. Stressbezogene Tätigkeitsanalyse [Stress-oriented activity analysis: psychological research on the analysis of stress at work]. Weinheim, Germany: Beltz.

Sonnentag, S. 2003. Recovery, work engagement, and proactive behavior. A new look at the interface between nonwork and work. Journal of Applied Psychology, 88: 518-528.

Sonnentag, S., \& Frese, M. 2003. Stress in organizations. In W. C. Borman, D. R. Ilgen, \& R. J. Klimoski (Eds.), Handbook of psychology (Vol. 12): 453-491. New York: Wiley.

Sparks, K., Cooper, C., Fried, Y., \& Shirom, A. 1997. The effects of hours of work on health: A meta-analytic review. Journal of Occupational and Organizational Psychology, 70: 391-408.

Turner, N., Barling, J., \& Sachaatos, A. 2002. Positive psychology at work. In C. Snyder \& S. J. Lopez (Eds.), Handbook of positive psychology: 715-730. New York: Oxford University Press.

Turner, N., Parker, S. K., \& Williams, H. M. 2002, August. Self-managing teams and workplace safety: An employee-level investigation. Paper presented at the 62nd Annual Meeting of the Academy of Management, Denver, CO.

Watson, D., \& Clark, L. A. 1992. Affects separable and inseparable: On the hierarchical arrangement of the negative effects. Journal of Personality and Social Psychology, 62: 489-505.

Watson, D., Clark, L. A., \& Tellegen, A. 1988. Development and validation of brief measures of positive and negative affect: The PANAS scales. Journal of Personality and Social Psychology, 54: 1063-1070.

Weiss, H. M., \& Cropanzano, R. 1996. Affective events theory: A theoretical discussion of the structure, causes, and consequences of affective experiences at work. In B. M. Staw \& L. L. Cummings (Eds.), Research in organizational behavior (Vol. 18): 1-74. London: JAI.

Weiss, H. M., Suckow, K., \& Cropanzano, R. 1999. Effects of justice on discrete emotions. Journal of Applied Psychology, 84: 786-794.

Williams, K. J., \& Alliger, G. M. 1994. Role stressors, mood spillover, and perceptions of work-family conflict in employed parents. Academy of Management Journal, 37: 837-868. 


\section{Biographical Notes}

Charlotte Fritz is an assistant professor in industrial and organizational psychology at Bowling Green State University. Her research on one hand focuses on relationships between off-work experiences and employee wellbeing and job performance. On the other hand, she is interested in predictors and outcomes of proactive and creative behaviors at work.

Sabine Sonnentag is a full professor of work and organizational psychology at the University of Konstanz, Germany. In her research, she is mainly interested in how individuals can achieve sustained high performance at work and remain healthy at the same time. Her major research topics include recovery and unwinding from work stress, job performance and its relationship to self-regulatory processes, and continuous learning and proactivity at work. 